India now finds herself. No one who has visited Bangalore can have failed to recognise the great pioneering work which Dr. Travers did there; but the fact that he was unable to carry through does not necessarily mean that, under different conditions, possibly determined by past experience, the outcome might not be different. JOCELYN THORPE.

Imperial College of Science and Technology,

South Kensington, London, S.W.7.

\section{Some Poetic Allusions to Phenomena of Plant Biology.}

IT is with a peculiar pleasure that one finds observations, ordinarily recorded in the precise words of scientific usage, appearing in the beautiful and fanciful diction of the poets. The following examples may be familiar to many, but I have not seen them mentioned elsewhere in this connexion.

It has been shown by A. R. C. Haas that the soluble pigments in many flowers act as indicators, and give a measure of the hydrogen ion concentration of the sap, which in some flowers becomes less as the petals age and wither. This colour change has been noted by Edmund Spenser, and in recent times by A. E. as follows:

\section{Astrophel.}

Transformed them, there lying on the field

Into one floure that is both red and blew;

It first grows red, and then to blew doth fade,

Like Astrophel, which thereinto was made.

The Great Breath.

Its edges foamed with amethyst and rose,

Withers once more the old blue flower of day :

There where the ether like a diamond glows

Its petals fade away.

The first is the imagery of mythology, the second uses the same illustration to contrast the brief life of a flower with the unending procession of days.

Again Tennyson gives us a description of the yew tree in stanza 2 of "In Memoriam," which contains these lines:

\section{O not for thee the glow, the bloom, \\ Who changest not in any gale, \\ Nor branding summer suns avail \\ To touch thy thousand years of gloom.}

Beyond this stanza the early edition makes no further detailed reference to the yew. Later editions, however, provide one additional stanza, a new thirtyninth being intercalated.

Old warder of these buried bones,

And answering now my random stroke

With fruitful cloud and living smoke,

Dark yew, that graspest at the stones

And dippest toward the dreamless head, To thee too comes the golden hour When flower is feeling after flower ; But Sorrow--fixt upon the dead,

And darkening the dark graves of men,What whisper'd from her lying lips ?

Thy gloom is kindled at the tips,

And passes into gloom again.

Here Tennyson guards against the too literal interpretation of " who changest not in any gale," and gives a wonderful description of the liberation of the pollen and its result of many months later, the formation of the red berry, red as a glowing tip on a piece of wood kindled by fire. The berry falls, the glow is quenched, and gloom follows. This natural sequence of pollen and berry, coupled with the use of the word " kindled," so suggestive of a fiery hue, makes it seem

$$
\text { NO. } 2857 \text {, VOL. I I } 4]
$$

impossible that Tennyson can have intended to allude to the lighter green of the young leaves-an explanation which, I believe, has been put forward.

To A. E. again we are indebted for the description of the recovery of turgor in plants wilted by the heat of day, which is contained in " A Summer Night" ;

The falling of innumerable dew,

Lifts with grey fingers all the leaves that lay

Burned in the heat of the consuming day.

We have all seen the " grey fingers," but it takes a poet to stamp the picture in an untarnishable phrase.

Finally, in "Prometheus Unbound," Shelley alludes to the liberation of oxygen in photosynthesis, imagining that the spirits " Which make such delicate music in the woods" dwell in bubbles, thus:

The bubbles, which the enchantment of the sun

Sucks from the pale faint water-flowers that pave

The oozy bottom of clear lakes and pools,

Are the pavilions where such dwell and float

Under the green and golden atmosphere

Which noon-tide kindles thro' the woven leaves;

And when these burst, and the thin fiery air, ...

Have we as yet got so very far beyond "the enchantment of the sun " as an explanation ?

Antony, Cornwall,

$$
\text { W. R. G. Atrins. }
$$

July I7.

\section{Electrical Properties of Thin Films.}

THE mechanical properties of thin films on the surface of water have been the subject of many investigations; yet little is known of their electrical properties. Whilst the electrical properties of those films which are formed on the surface of soluble capillary active substances can be readily investigated, using a method elaborated by Kenrick (Zeitschr. f. physik. Chem., xix. 625), no method, so far as I know, has yet been described which can be applied to

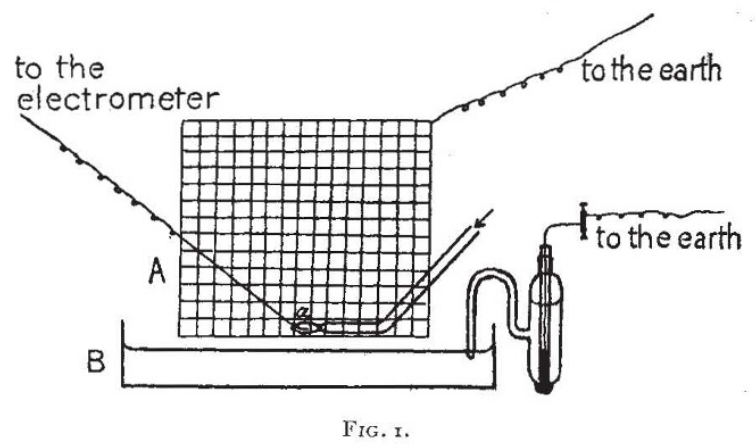

films formed by insoluble substances. The follow. ing simple arrangement has been designed which has given quite satisfactory results in this case.

A thin platinum wire $a$ was heated to white-heat by a minute gas flame in an earthed Faraday cage $A$ hung over the surface of water in the vessel $B$ (Fig. I). The platinum wire was connected with a quadrant electrometer, and the water in the vessel with the earth through a decinormal calomel electrode. Between the earth and the electrode, a variable electromotive force could be inserted. The experiments have shown that the potential of the wire follows closely the variations of the potential of the water surface when the distance between the platinum wire and the water surface does not exceed 7-8 $\mathrm{mm}$.

If we put now a droplet of oil on the water surface, the electrometer shows instantly a change of the potential of the wire. In order to compensate this 